\title{
Optimization of Healthy Service by Implementing the System Queues on Social Insurance Administration Organization (BPJS) in Dr. H. Marzoeki Mahdi Hospital in Bogor
}

\author{
Ani Andriyati, Suci Lisdawati
}

\begin{abstract}
Patient queue buildup on Social Insurance Administration Organization (BPJS) in the Dr. $H$. Marzoeki Mahdi hospital (RSMM) in Bogor is a problem that often occurs. This is caused by the patient's arrival rate exceeds the service facilities provided. To reduce the buildup of queues and improve services, queueing M/M/S model is applied in BPJS patient. M/M/S model is used so that the Ministry can optimize the management system as well as reduce queues at the BPJS patients patient service (TPP) in Bogor RSMM. On-site system queues on the TPP can be done at a time when the number of staff service (counter) at least 5 officers of service so that in addition to be able to reduce the chance of a busy period of previous service officer can also optimize on-site services, but for the wait and cost expenditures costs of facilities not significant therefore need to add 1 more Ministry officials became 6 officer's service in order to improve the facilities of the Ministry on patients as well as patients BPJS TPP not too long to wait in the process the queue.
\end{abstract}

Index Terms: BPJS, Queueing Theory, M/M/S Model

\section{INTRODUCTION}

The Dr. H. Marzoeki Mahdi hospital (RSMM) in Bogor is one of state hospital that became one of the Social Insurance Administration Organization (BPJS) reference patient. Registration Place of Patients on RSMM only has 3 registration services (counters) for the BPJS members and the general patients. Many patients in RSMM use BPJS service because it is very helpful in health services for the society especially for the poor. The BPJS member's queue occurred because the need for service exceeds that of service facilities that are caused by servant's occupations. The duration of the waiting time depends on the activities to achieve the service on a queue. The problem is how to be able to cultivate a balance the costs of waiting for the facilities to give optimal service. One way to improve the good service facilities is using queueing models of $\mathrm{M} / \mathrm{M} / \mathrm{S}$ which is a method for system management service can optimize in order to reduce the queue [1]. In contrast to [1], in this research note that queueing system is at fixed or conditions in a stable state that all BPJS members served well.

\section{MATERIALS AND METHOD}

The data used as the number of the patient's arrival in November 2015 at 07.00-13.00 at the Dr. H. Marzoeki Mahdi hospital (RSMM) in Bogor then observed the observation of the patient service's time on TPP in RSMM as in Table 1.

Table 1 Data of The number of customers and the average of patient Service time

\begin{tabular}{|c|c|c|}
\hline Day & $\begin{array}{l}\text { The Number of BPJS } \\
\text { customer in } 6 \text { hours }\end{array}$ & $\begin{array}{c}\text { The average of patient } \\
\text { Service time }\end{array}$ \\
\hline 1 & 503 Patients & 3 minute 27 second \\
\hline 2 & 508 Patients & 2 minute 25 second \\
\hline 3 & 430 Patients & 2 minute $\mathrm{t} 47$ second \\
\hline 4 & 491 Patients & 2 minute t 57 second \\
\hline 5 & 443 Patients & 3 minute 10 second \\
\hline 6 & 507 Patients & 3 minute 28 second \\
\hline 7 & 495 Patients & 2 minute 57 second \\
\hline 8 & 419 Patients & 2 minute 25 second \\
\hline 9 & 448 Patients & 3 minute 18 second \\
\hline 10 & 383 Patients & 2 minute 34 second \\
\hline 11 & 511 Patients & 3 minute 24 second \\
\hline 12 & 521 Patients & 3 minute 29 second \\
\hline 13 & 423 Patients & 2 minute 54 second \\
\hline 14 & 463 Patients & 3 minute 39 second \\
\hline 15 & 394 Patients & 2 minute 46 second \\
\hline 16 & 470 Patients & 2 minute 35 second \\
\hline 17 & 479 Patients & 4 minute 15 second \\
\hline 18 & 482 Patients & 3 minute 33 second \\
\hline 19 & 443 Patients & 3 minute 36 second \\
\hline 20 & 427 Patients & 2 minute 46 second \\
\hline 21 & 466 Patients & 3 minute 25 second \\
\hline
\end{tabular}

The cost of facilities that were issued by the hospital involved the salary of registration officer amounted to IDR $2,000.00$ per month, the cost of procurement of facilities in the form of tables, chairs, computer, and printer machine amounted to IDR 11,000,000 per procurement, as well as the cost of waiting time incurred by patients is assumed to be of Regional Bogor Minimum Wage which is amounted to IDR 2,600,000.00 per month. 
Stages Of Analysis:

1. Collecting data that is in the form of observations to find out the number of arrival and time of the BPJS member service on registration site in the Dr. H. Marzoeki Mahdi hospital (RSMM) in Bogor.

2. calculate the average of the arrival time by the formula: $\lambda=\frac{\text { the number of customers }}{}$

3. Test the distribution of arrival pattern by assuming that the number of arrivals are random or by calculating the probability of poisson distribution [2] by the formula:

$P(x)=\frac{e^{-\lambda} \lambda^{x}}{x !}$

Details:

$P(x)$ : the probability of $\mathrm{x}$ arrival

$x \quad$ : The number of arrival per time unit

$\lambda \quad$ : The average of the arrival time of the customers : 2,7183

Test the poisson distribution on arrival of BPJS member by the formula:

$\chi^{2}=\sum \frac{\left(x_{i}-\bar{x}\right)^{2}}{\bar{x}}$

The decision criteria done by receipt the average of service follow poisson distribution if $\chi^{2}$ hitung $\leq \chi^{2}$ tabel. Then calculate the service of BPJS member by finding the expected value with the formula:

$$
P(t)=\mu e^{-\mu t}
$$

Details:

$\mathrm{t}$ : service time

$\mu \quad$ : the average of service level

e : 2,7183

Do the exponential test by the formula:

$\chi^{2}=\Sigma \frac{\left(\mu_{i}-\mu_{i \text { expected }}\right)^{2}}{\mu_{i \text { expected }}}$

The decision criteria done by receipt the average of service follow poisson distribution if $\chi^{2}$ hitung $\leq \chi^{2}$ tabel .

4. The application of queuing model in multiple line that is using $\mathrm{M} / \mathrm{M} / \mathrm{S}$ model [3]. The first is calculate the average of the customer's arrival time $\lambda$, then finding the average of service by the formula:

$\mu=\frac{1}{\text { the average of customer service time }}$

The next is calculate the probability of busy time by this formula [4]: $\rho=\frac{\lambda}{s \mu}$ by the stipulation $\left(\frac{\lambda}{s \mu}<1\right)$ to check queue system whether on stable state or not. The calculation of the probability of no individual in the system by this formula: $P_{0}=\frac{1}{\left[\sum_{n=0}^{s-1} \frac{1}{n !}\left(\frac{\lambda}{\mu}\right)^{n}\right]+\frac{1}{s !}\left(\frac{\lambda}{\mu}\right)^{s}\left(\frac{s \mu}{s \mu-\lambda}\right)}$, the probability of waiting on system by this formula:
$P_{w}=\frac{1}{s !}\left(\frac{\lambda}{\mu}\right)^{s}\left(\frac{s \mu}{s \mu-\lambda}\right) P_{0}$

The average of the individual number in system by this formula:

$L_{s}=\frac{\lambda \mu(\lambda / \mu)^{s}}{(s-1) !(s \mu-\lambda)^{2}} P_{0}+\frac{\lambda}{\mu}$

The average of the individual number in queue by this formula:

$L_{q}=L_{s}-\frac{\lambda}{\mu}$

The average of the time on system by this formula:

$$
W_{s}=\frac{L_{S}}{\lambda}
$$

The average of the time on queue by this formula:

$$
W_{q}=W_{s}-\frac{1}{\mu}
$$

Calculation of the cost analysis [5] by the formula: $E\left(C_{t}\right)=E\left(C_{w}\right)+E\left(C_{s}\right)$ by knowing the costs of onsite service per hour by this formula [6] $: E\left(C_{s}\right)=S x C_{S}$ and the costs of waiting the member per hour by this formula : $E\left(C_{w}\right)=n_{t} x C_{w}$.

5. Make the conclusion to find out the result of calculation using $\mathrm{M} / \mathrm{M} / \mathrm{S}$ model and calculate the total costs in order to the waiting costs and facilities costs are significant.

\section{RESULTS AND DISCUSSION}

\section{A. Calculate The Average Of Arrival Time}

The average of the arrival time every day by (1) formula. In example, calculation of the average of the arrival time day one as:

$$
\begin{aligned}
(\lambda) & =\frac{503 \text { patients }}{6 \text { hours }} \\
& =83,83 \text { patients per hour } \\
& \approx 84 \text { patients per hour }
\end{aligned}
$$

Then calculate the average of the arrival of the BPJS members per hour for 21 days so that obtained results of the overall average for the level of the BPJS member's arrival for 21 working days i.e. as many as 78 patients per hour on each day.

\section{B. Suitable Test Of Poisson Arrival Level}

Calculate the probability of patient's arrival, the probability is calculated by calculating the average patient's arrival by entering a value $(\lambda)$ from a previous calculation of results as well as the value (x) is the number of arrivals per time unit (per person) from the average arrival time of BPJS member as many as 78 patients.

Calculation of the poisson probability function of arrival pattern using the formula (2) is as follows:

$$
\begin{aligned}
P(x) & =\frac{e^{-78} 78^{1}}{1 !} \\
& =1,03968 \mathrm{E}-32
\end{aligned}
$$

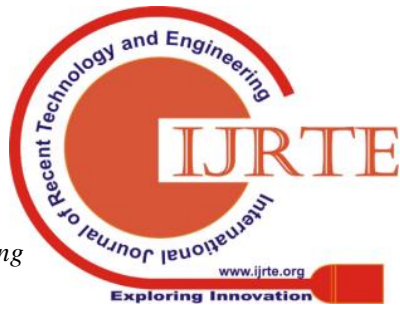


Based on the calculation, the probability value is 1.03968E-32. Based on the value of probability, gained the distribution curves for arrival as can be seen in Fig. 1.



Fig. 1. BPJS Member Arrival Poisson Distribution Curve

Horizontal line on Fig. 1 is the arrival of customers while the vertical line is the value of the probability. The shape of the curve resembles the shape of a bell-like and never cut a horizontal axis so that the arrival pattern is poisson distribution. Test the suitability of poisson on the real level of $5 \%$ for the arrival of the patient retrieved value $\chi_{\text {hitung }}^{2}=11,54<\chi_{\text {tabel }(20)}^{2}=31,41$. These results indicate the arrival patterns of patients is poisson distribution with arrival patterns are random can vary on per hour at the speed of an average arrival time.

\section{Calculates the average value of Service Time}

Calculation of the probability of the service time, the probability $\mu_{i \text { expected }}$ is calculated by calculating the average patient service time by entering the value $(\mu)$ derived from the results of observation and the value of $(t)$ have been determined by taking the value of $\mathrm{t}=1$.

calculation of the expected service time for day 1 using the formula (4) as follows:

$$
\begin{aligned}
P(t) & =3,27 e^{(-3,27)(1)} \\
& =0,124
\end{aligned}
$$

The probability of total average time of service is expected on TPP that is amounted to 3.457 .

The exponential suitability test needs to be done to find out the time of patient's service is exponential or not. Based on the calculation of exponential suitability test obtained the result $\chi_{\text {hitung }}^{2}=47,64<\chi_{\text {tabel }(20)}^{2}=31,41$ so that it can be said the service time on patient does not follow exponential distribution. It means that the service time can be changed.

\section{M/M/S Queuing Model}

The first calculation is determine the value of the average ( $\lambda$ ) level of BPJS member arrivals as much as 78 patients per hour. Average time of patient service with formulas (6) obtained: $\mu=\frac{1}{3,31}=0,302$ patient per minute or $\mu=0,302 \times 60=$ 18,12 patient per hour. Based on the calculation is obtained the average of patient service time is 18,12 patient per hour.

The next step is checking whether the system in patient service place in hospital has been on the stable state with the service officer (counter) as much as 3 service officers $(s=3)$. Based on the calculation, acquired the probability of busy time amounting to 1.43 . It means that $1.43>1$ means an average rate of arrival is maximum potential in doing service so that patient queues will continue to occur. This queue system are not on fixed conditions (steady state) because the terms are not fulfilled. In order to get the results that the queue is on a fixed condition then the alternative is changing the number of staff of the service officer. To find out the number of service officer (counter) performed the calculation $s>\frac{\lambda}{\mu}$ so that the retrieved $\mathrm{s}>4.30$. The results showed that the steady state condition occurs when the number of staff of the service officer with an integer number i.e. 4.30 and rounded up into 5 service officers.

By placing 5 service officer (counter) TPP at the hospital obtained the value of busy time probability is amounted to 0.86 . The value of probability is less than 1 , thereby the requirement for fixed conditions (steady state) have been fulfilled. It means that the working hours of service officers to serve a queue approximately 0.86 or $86 \%$. The State of the systems that have been at the maximum of the circumstances or conditions remain stable (steady state).

The computation of $(\mathrm{M} / \mathrm{M} / \mathrm{S})$ queue model using 5 officer service (counter) is obtained that the probability of no individual within the system $\left(P_{0}\right)$ is $0.76 \%$, the probability of patients waiting for the turn to be served $\left(P_{w}\right)$ is $67.3 \%$, the average number of patients waiting in the system $\left(L_{s}\right)$ to be served by the officer in TPP is 9 patients, the average patient waiting in a queue $\left(L_{q}\right)$ to be served by the officer is 5 patients, the patients waiting in the queue system $\left(W_{s}\right)$ during 0.11 hours or 6.6 minutes, patients waiting $\left(W_{q}\right)$ in the queue during 0.055 hours or 3.3 minutes.

\section{E. Cost Analysis}

The Calculation of the cost analysis, namely income derived from earning an average income take patients with UMR Bogor for a month, that is IDR 2,600,000.00 per person. Assuming 30 working days and 8 hours per day then the patient's earnings per hour amounted to $=\frac{86.666,67}{8}=\mathrm{IDR}$ $10,834.00$ per hour. So, the cost of waiting must be paid by the patient $E\left(C_{w}\right)$ is IDR $91,786.00$ per hour.

The income of officer service (counter) TPP in Hospitals is IDR 2,000,000.00 per month. Based on the Calculation of patient service officer (counter) RSMM, the income is IDR $8,334.00$ per hour. So that, the cost of the facility is issued using the 5 officers service (counter) $E\left(C_{s}\right)$ is IDR 41,670.00 per hour. The cost of the equipment with the addition of 2 patient service officer (counter) TPP is IDR 22,000,000.00. So that, the total estimated operariougt and costs that must be incurred $E\left(C_{t}\right)$ is IDR $133,456.00$ 


\section{Optimization of healthy service by Implementing the System Queues on Social Insurance Administration Organization (BPJS) in Dr. H. Marzoeki Mahdi Hospital in Bogor}

M/M/S Queuing model using 5 service officer(counter) that have been simulated by service facilities has not been significant because the waiting costs greater than the expense cost of the facility so that the total cost of the queue is not balanced. It is needed to add 1 service officer (counter) into 6 service officer (counter).

If the number of service officers is 6 officer then working hours is used by officers to serve the queue is 0.72 , the probability of no individual within the system $\left(P_{0}\right)$ is $1.2 \%$, the probability of patients waiting for the turn to be served $\left(P_{w}\right)$ is $37.5 \%$, the average number of patients waiting in the system $\left(L_{s}\right)$ to be served by the service officer is 6 patients, the average patient waiting in a queue $\left(L_{q}\right)$ to be served by the officer is 1 patient, a patient waiting in queue system $\left(W_{s}\right)$ during 0.067 hours or 4.02 minutes, patients waiting in the queue $\left(W_{q}\right)$ during 0.012 hours or 0.72 minutes.

The cost of waiting must be paid by the patient $E\left(C_{w}\right)$ is IDR 56,966.00 per hour. The cost of the facilities must be paid using the 6 service officers (counter) $E\left(C_{s}\right)$ is IDR $50,004.00$ per hour. And the cost of the equipment with the addition of 2 patient service officers (counter) TPP $E\left(C_{s}\right)$ is IDR 33,000,000.00. Thus, total estimated operational costs that must be paid $E\left(C_{t}\right)$ is IDR $106,970.00$ per hour.

Optimal service levels on TPP acquired by determining the intersection point between the red line and the blue line in Fig. 2.

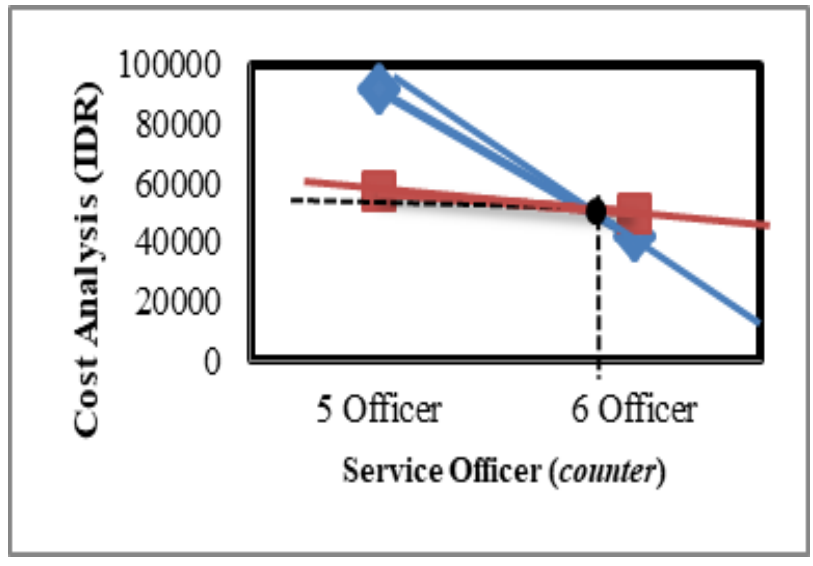

Fig. 2. Cost of characteristic and Optimal Service Level

In Figure 2, the axis (x) describes the number of service officers on the TPP in the Dr. H. Marzoeki Mahdi hospital (RSMM) in Bogor, while axis (y) Is the cost analysis which includes the costs of waiting and the cost of the facilities of the previous calculation result. The blue line is the cost of using 5 service officers and the red line is the cost of using 6 service officers. Based on Figure 2, retrieved a balance point or optimum service level that is approaching 6 service officers (counter).

\section{CONCLUSION}

The queuing system using a M/M/S model at the on-site Registration BPJS member (TPP) in the Dr. H. Marzoeki Mahdi hospital (RSMM) in Bogor. Arrival level and service time follow the poisson distribution. It means that arrival level and service time are random and can vary on each hour of its speed on the average arrival time. If BPJS uses 3 service officer (counter), the probability of service patient registration is exceeds the maximum potential of service so that queues are not in the stability condition (steady state), which means the number of patient's arrival is maximum. Therefore it's needed to add of 2 service officers (counter) in order to reduce the overload queues. By the additions of 2 service officers (counter) into 5 service officers (counter) on the TPP can improve patient's service because it reduces the probability of a busy period of previous service officers, however the cost of waiting and the cost of the facilities that must be paid are not optimal, so that it's needed to add of 1 service officers more into 6 officers (counter) so that the cost of waiting and the cost of the facility is balance.

\section{REFERENCES}

1. M. Susanti, Application of queuing models and cost analysis on Service Cashier at the post office Branch Curug-Tangerang. Bogor: Pakuan University, 2013.

2. J. Supranto, Research Operation for decision maker. Jakarta: Indonesia University, 1998

3. Aminudin. The Principals of Research Operation. Jakarta: Erlangga, 2005.

4. R. Bronson and J. H. Wosparkrik. Theory and Question of Research Operation. Jakarta: Erlangga Publisher, 1998.

5. V. Gaspers. Managerial Economics for Business Decision Makers. Jakarta: Gramedia Pustaka, 1997.

6. Siswanto. Research Operations. Jakarta: Erlangga Publisher, 2007. 